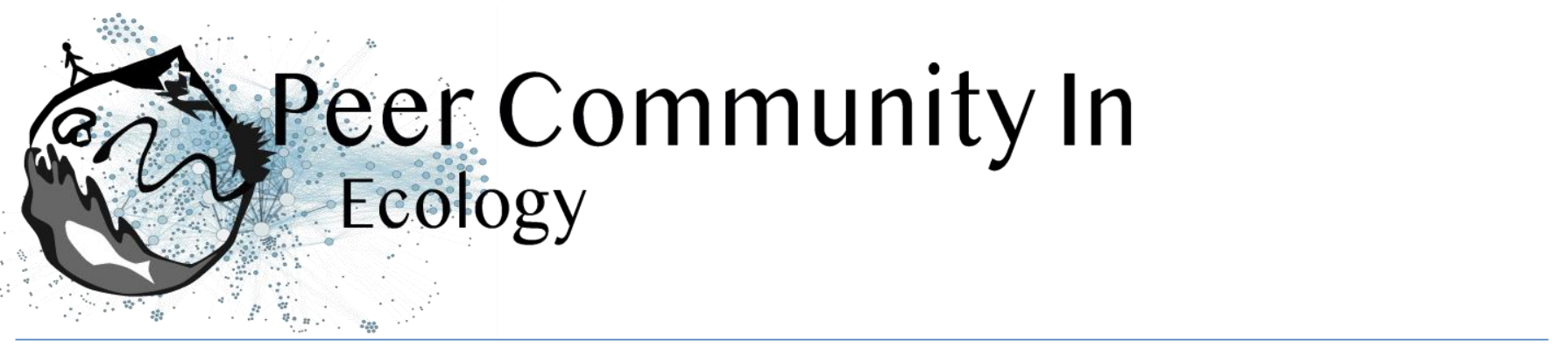

\title{
The promise and limits of DNA based approach to infer diet flexibility in endangered top predators
}

\author{
Sophie Arnaud-Haond based on reviews by Francis John Burdon and Babett \\ Günther
}

\section{A recommendation of:}

Metabarcoding faecal samples to investigate spatiotemporal variation in the diet of the endangered Westland petrel (Procellaria westlandica)

Marina Querejeta, Marie-Caroline Lefort, Vincent Bretagnolle, Stéphane Boyer (2021), bioRxiv, 2020.10.30.360289, ver. 4 peer-reviewed and recommended by Peer Community

\section{Open Access} in Ecology https://doi.org/10.1101/2020.10.30.360289

Submitted: 30 October 2020, Recommended: 23 November 2021

Published: 2 December 2021

Copyright: This work is licensed under the Creative Commons Attribution-NoDerivatives 4.0 International License. To view a copy of this license, visit http://creativecommons.org/licen ses/by-nd/4.0/
Cite this recommendation as:

Sophie Arnaud-Haond (2021) The promise and limits of DNA based approach to infer diet flexibility in endangered top predators. Peer Community in Ecology, 100090. https://doi.org/10.24072/pci.ecology.100090

\section{Recommendation}

There is growing evidence of worldwide decline of populations of top predators, including marine ones (Heithaus et al, 2008, Mc Cauley et al., 2015), with cascading effects expected at the ecosystem level, due to global change and human activities, including habitat loss or fragmentation, the collapse or the range shifts of their preys. On a global scale, seabirds are among the most threatened group of birds, about one-third of them being considered as threatened or endangered (Votier\& Sherley, 2017). The large consequences of the decrease of the populations of preys they feed on (Cury et al, 2011) points diet flexibility as one important element to understand for effective management (McInnes et al, 2017). Nevertheless, morphological inventory of preys requires intrusive protocols, and the differential digestion rate of distinct taxa may lead to a large bias in morphological-based diet assessments. The use of DNA metabarcoding on feces (or diet DNA, dDNA) now allows non-invasive approaches facilitating the recollection of samples and the detection of multiple preys independently of their digestion rates (Deagle et al., 2019). Although no gold standard exists yet to avoid bias associated with metabarcoding (primer bias, gaps in reference databases, inability to differentiate primary from secondary predation...), the use of these recent techniques has already improved the knowledge of the foraging behaviour and diet of many animals (Ando et al., 2020).

Both promise and shortcomings of this approach are illustrated in the article "Metabarcoding faecal samples to investigate spatiotemporal variation in the diet of the endangered Westland petrel (Procellaria westlandica)" by Quereteja et al. (2021). In this 
work, the authors assessed the nature and spatio-temporal flexibility of the foraging behaviour and consequent diet of the endangered petrel Procellaria westlandica from New-Zealand through metabarcoding of faeces samples.

The results of this dDNA, non-invasive approach, identify some expected and also unexpected prey items, some of which require further investigation likely due to large gaps in the reference databases. They also reveal the temporal (before and after hatching) and spatial (across colonies only $1.5 \mathrm{~km}$ apart) flexibility of the foraging behaviour, additionally suggesting a possible influence of fisheries activities in the surroundings of the colonies. This study thus both underlines the power of the non-invasive metabarcoding approach on faeces, and the important results such analysis can deliver for conservation, pointing a potential for diet flexibility that may be essential for the resilience of this iconic yet endangered species.

\title{
References
}

Ando H, Mukai H, Komura T, Dewi T, Ando M, Isagi Y (2020) Methodological trends and perspectives of animal dietary studies by noninvasive fecal DNA metabarcoding. Environmental DNA, 2, 391406. https://doi.org/10.1002/edn3.117

Cury PM, Boyd IL, Bonhommeau S, Anker-Nilssen T, Crawford RJM, Furness RW, Mills JA, Murphy EJ, Österblom H, Paleczny M, Piatt JF, Roux J-P, Shannon L, Sydeman WJ (2011) Global Seabird Response to Forage Fish Depletion-One-Third for the Birds. Science, 334, 17031706. https://doi.org/10.1126/science.1212928

Deagle BE, Thomas AC, Mclnnes JC, Clarke U, Vesterinen EJ, Clare EL, Kartzinel TR, Eveson JP (2019) Counting with DNA in metabarcoding studies: How should we convert sequence reads to dietary data? Molecular Ecology, 28, 391-406. https://doi.org/10.1111/mec.14734

Heithaus MR, Frid A, Wirsing AJ, Worm B (2008) Predicting ecological consequences of marine top predator declines. Trends in Ecology \& Evolution, 23, 202-210. https://doi.org/10.1016/j.tree.2008.01.003

McCauley DJ, Pinsky ML, Palumbi SR, Estes JA, Joyce FH, Warner RR (2015) Marine defaunation: Animal loss in the global ocean. Science, 347, 1255641. https://doi.org/10.1126/science.1255641

McInnes JC, Jarman SN, Lea M-A, Raymond B, Deagle BE, Phillips RA, Catry P, Stanworth A, Weimerskirch H, Kusch A, Gras M, Cherel Y, Maschette D, Alderman R (2017) DNA Metabarcoding as a Marine Conservation and Management Tool: A Circumpolar Examination of Fishery Discards in the Diet of Threatened Albatrosses. Frontiers in Marine Science, 4, 277. https://doi.org/10.3389/fmars.2017.00277

Querejeta M, Lefort M-C, Bretagnolle V, Boyer S (2021) Metabarcoding faecal samples to investigate spatiotemporal variation in the diet of the endangered Westland petrel (Procellaria westlandica). bioRxiv, 2020.10.30.360289, ver. 4 peer-reviewed and recommended by Peer Community in Ecology. https://doi.org/10.1101/2020.10.30.360289

Votier SC, Sherley RB (2017) Seabirds. Current Biology, 27, R448R450. https://doi.org/10.1016/j.cub.2017.01.042

\section{Reviews}

Toggle reviews

\author{
Evaluation round \#2 \\ DOI or URL of the preprint: https://doi.org/10.1101/2020.10.30.360289
}

Version of the preprint: 2 


\section{Author's Reply}

Download author's replyDownload tracked changes file

\section{Decision by Sophie Arnaud-Haond, 02 Nov 2021}

Dear Marina Querejeta and colleagues,

Your article has now been reviewed for the second time by two referees and myself. All acknowledge the large improvements made on the MS, including a spectacular improvement in data analysis and results thanks to the referee's advise. Nevertheless, both referee still have a couple of concern I believe deserve to be seriously accounted for.

Following referee 1 advise, please pay attention to the use of terms such as read abundance and biomass, and necessary details in the description of what has been done: for example manual curation of data requires detailed information on the strategy adopted, the rationale behind it, and the steps leading from raw to exploited data (and associated information on taxa discarded). Discarding arbitrarily OTUs that are considered as contaminant because they are not potential prey, to the best of your knowledge, is not acceptable. You may want to use a specific package such as decontam to make an objective work and discuss uncertainties about remaining OTUs. Referee 1 also ask a set of relevant technical questions in need for an answer and more detailed \& clearer explanation of the steps followed, keeping in mind that anybody with the article in hands would be able to repeat exactly the work starting with raw data and the material and method section.

Referee 2 still has two very important comments, beyond other relevant minor comments: the first one is the uncertainty around the assignment to Talitrid, the second is the interpretation (would the assignment be ascertained) in terms of dependence to fisheries and cascading impacts of the change in diet for petrels. First of all, I suggest the authors to carefully revise the manuscript replacing the taxa name ' $x x^{\prime}$ ' by 'assigned to $x_{x x}$ ', particularly when the homology is low and the assignment to the genera or family level, which is clearly the case for Talitrids. This phrasing helps to keep in mind the uncertainties we are dealing with. Second, the authors may think through the hypothesis and suggestions made by referee2, to improve data analysis and revise part of the discussion. The authors may for example consider extracting the fasta sequences of these ASVs and align them against a homemade database for amphipods, in order to ascertain manually the level of homology and the closest possible relative. Such homemade database may as much as possible strongly favour sequences of high-level confidence taxonomic inference, such as holotypes, in order to avoid badly assigned sequences in the public databases. Given the $78-86 \%$ homology that is low, it is in fact impossible to ascertain these OTUs really belong to Talidrid rather than any other closely related family absent from 165 reference databases. Would the uncertainty remain the same, a leveraged and more cautious discussion (with a lighter mention to the possibility of Talidrid dominance in the diet) would be advisable. Would the uncertainty be much lower, and the Talidrid assignment be confirmed with a much higher level of certainty, the discussion may include the path suggested by referee 2.

I will finish with a first general advice, following a first submission of the wrong file and a second submission with a track changes files that contains only a subset of the changes made since the primary submission, and personal comments exchanged among coauthors. This reflects badly on the carefulness of the prime author and on the attention dedicated to the review process.

I thus urge you to carefully account for the comments of referee, and to prepare a carefully checked last version with very clear track changes compared to this one. A simple option is to compare the very last version to the very first one with Word, allowing a clean and complete file with track changes without omitting important ones and including personal comments.

Soiphie Arnaud-Haond 


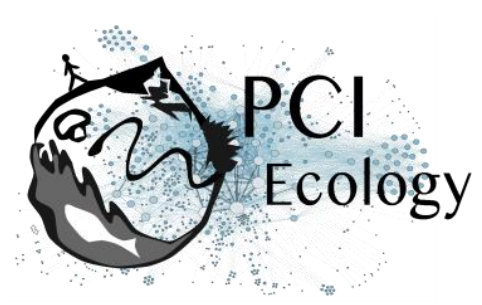

Reviewed by Babett Günther, 18 Oct 2021

Download the review

Reviewed by Francis John Burdon, 17 Oct 2021

Download the review

Evaluation round \#1
DOI or URL of the preprint: https://doi.org/10.1101/2020.10.30.360289

Version of the preprint: 1

\section{Author's Reply}

Download author's replyDownload tracked changes file

\section{Decision by Sophie Arnaud-Haond, 03 Jan 2021}

Dear Marina Querejeta and colleagues, Your article has now been reviewed by two referees and myself. Both referee have found your approach valuable and results of interest and they both have serious and complementary recommendations to ascertain or improve data and interpretations. Based on their reviews and my lecture, I suggest this preprint deserves a revision. I hope comments below and referee's detailed suggestions will help. I suggest you follow those very detailed suggestions. Particularly, referee 1 suggest detailed paths to re-analyze data and make sure a large set of sequences could not have been lost in the first bioinformatic steps, introducing a bias in the prey recognized with the sequences left. Reading the MS, I found no information on the way primers were treated and understand this wonder particularly considering the $300 \mathrm{bp}$ limit and the $2 \mathrm{M}$ merged reads for nearly $10 \mathrm{M}$ raw ones. This raises the point of access to data and bioinformatic scripts, that will eventually be required and would ease the review process. Would referee1 be right on his guess, results may come strongly different in terms or RAA and dominant preys, thus I suggest to follow his recommendation and make data and script available for the next round of submission. Referee 1 also made a number of suggestions to improve the MS. Among other the use of eDNA is confusing when it comes to diet, for stomach content or poo are not exactly environmental. The use of dDNA was recently coined by Sousa et al (2019, see below) for dietary DNA, and may be a nice option? Referee 2 is more worried by the dominance of Talitridae in the inferred diet. First of all, i) looking at Table 1, these assignments seem to suffer from a small \% of identity (around $80 \%$, which means it may be a different family?) and ii) they were performed on NCBI database that is not curated and contains sometimes sequences associated to highly misleading identifications. Considering the dominance of the sequence of these OTUs in the dataset, despite the acknowledgement for possible secondary predation in the discussion (that would, I agree with referee 2, still sound even more awkward from cephalopods and fishes), it may be advisable to also blast the results on curated or at least reduced databases such as Silva or Midori, in order to check these assignments, or to blast them individually and check the status/level of confidence of the blasted sequences (for example are there holotypes among those?). Would such taxa remain as dominant in the revised results, discussion should emphasize this level of uncertainty to clarify the assignment does not necessarily imply the taxa at the origin of the sequence is a sandhopper or a grandhopper. Referee 2 also made suggestion to improve the indirect evidence offered by metabarcoding by producing predictions for prey size, that may be interesting to consider. Finally, it seems this family of amphipod has exhibited range shifts associated to climate change and/or human activities in the Northern hemisphere (the baltic sea). I 
wondered if such report would exist in the Southern hemisphere Sousa LL, Silva SM, Xavier R. 2019. DNA metabarcoding in diet studies: Unveiling ecological aspects in aquatic and terrestrial ecosystems. Environmental DNA 1:199-214.

\section{Reviewed by Francis John Burdon, 06 Dec 2020}

The authors have used metabarcoding of environmental DNA from fecal samples of tāiko (Procellaria westlandica), an endangered New Zealand seabird, to better understand its foraging behavior and trophic ecology. Two seasons and two sub-colonies were compared to assess temporal and spatial variation in the potential diets of tāiko. The authors found that surprisingly, talitrid amphipods dominated both the frequency of occurrence and relative number of sequence reads in the fecal samples from tāiko. However, more consistent with expectations, fish and cephalopods were also significant components of tāikos diet with an important commercial deep-sea species (hoki) featuring prominently, thus suggesting a potential conflict with the fishing industry due to bycatch.

Whilst these are useful insights, the dominance of the Talitridae in the diet of tāiko is problematic. These amphipods, commonly known as sandhoppers or landhoppers, could be secondary prey (e.g., prey of fish) caught by tāiko, raising the specter of the troublesome "Russian dolls" problem in food-web ecology. However, that explanation is unsatisfactory, because it is difficult to imagine their fish and cephalopod prey relying on subsidies of terrestrial amphipods. I wondered if the problem could be more prosaic, reflecting a technical issue with the extraction of DNA. For instance, the chitonous exoskeleton of the amphipods might not be fully digested by tāiko, meaning that this could lead to their DNA being overrepresented in the fecal samples. Such a problem could be exacerbated if the fecal samples were not fully homogenized before DNA extraction - it is unclear presently how the authors addressed this methodological issue (see L165-174). I also wondered how well described the Amphipoda are in the reference sequence databases used - could there be challenges on the bioinformatics side? If there was greater taxonomic resolution regarding the Talitridae, it might be possible to better understand where these putative prey come from - are they leaf-litter dwelling "landhoppers" or coastal "sandhoppers"?

Even if such technical issues do not explain the frequency and relative abundance of the Talitridae in environmental DNA from fecal samples of tāiko, it does highlight the potential limitations of this approach for characterizing food-web linkages. Other approaches, relying on biomarkers such as stable isotopes and fatty acids would be very useful for understanding the trophic ecology of this species by providing a timeintegrative perspective. This approach might also be useful to understand the energy flow between foraging adults and recipient young - in the present study it is unclear if fecal samples were collected from adults or juveniles.

The use of prey traits could be another potential line of evidence that would be useful for better understanding the trophic ecology of tāiko. For instance, using optimal foraging models, it might be possible to predict the body size of prey most profitable for tāiko - which presumably is in a size range larger than the amphipods. A trait-based approach (e.g., using prey body size) would also help better understand how ontogeny might influence the diet of tāiko, since environmental DNA says nothing about the life stage of prey (i.e., are there size-refugia?). I am unware if such approaches have been applied to seabirds, but it would be a powerful way to leverage the novelty of metabarcoding environmental DNA data from fecal samples. For further information I can recommend Petchey et al. (2008). Size, foraging, and food web structure. Proceedings of the National Academy of Sciences 105:4191-4196. Alternatively, for a more simple, descriptive approach see Table 1 in van Donk et al. (2017) The most common diet results in low reproduction in a generalist seabird. Ecology and Evolution 7:4620-4629

The use of environmental DNA for understanding trophic ecology is an exciting new development in conservation. However, the present study possibly raises more questions than it answers, indicating that further analysis and follow-up studies are required. If tāiko are indeed strongly reliant on talitrid amphipods in their diets, then there could be concerns about whether this is sufficient to meet their nutritional needs (e.g., as opposed to a diet rich in polyunsaturated fatty acids from marine sources). As actionable 


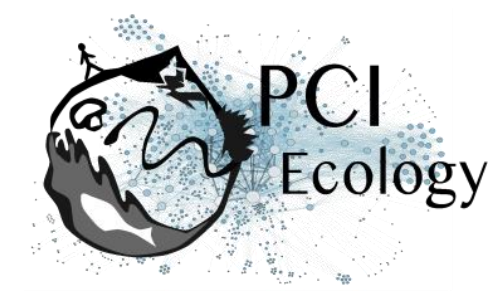

suggestions, I recommend the authors consider if prey traits could add to their story (e.g., is it possible to model an optimal prey size for tāiko and then compare that information with the data generated by environmental DNA), and also explore if supplementary data (e.g., tracking data or direct observations) are suggestive of possible foraging by tāiko in the coastal environment or leaf-litter near their burrows, where they would most likely encounter talitrid amphipods. I found at least one publication where nearshore foraging activity by petrels was recorded, although it is by no means a silver bullet to the problem at hand. see Thomas et al. (2006) Evidence for nocturnal inter-tidal foraging by European Storm-Petrels Hydrobates pelagicus during migration. Atlantic Seabirds 8:87-94.

With these major concerns raised, I have outlined some more minor comments and suggestions for the authors below.

Minor comments

L25 I think it might be not be totally accurate to call these impacts direct effects, since indirect effects are definitely plausible (e.g., changes in the diets of competitors could indirectly affect tāiko).

L27-29 I think this point could be made more effective by explicitly mentioning the spatial component (e.g. their mobility and foraging behavior enable tāiko to exploit prey distributed patchily in time and space)

L38 "geographical” = spatial

L48-51 I would consider breaking up this sentence e.g., "This work demonstrates the potential for environmental DNA to inform the conservation of endangered species with elusive foraging behaviors. In our example, environmental DNA provided valuable information regarding the diet preferences of an iconic species contributing to New Zealand's unique biodiversity."

L56 Could drop "in particular" since it is redundant

L61 Consider making a new paragraph here (also at L77, L98, and L136).

L144 The sub-colonies are only $1.5 \mathrm{~km}$ apart yet there seems to be some differences in their diets. Has anyone compared the population genetics of these two populations - presumably there is quite a lot of mixing? Was any attempt made to identify the fecal samples to the individual birds - since this non-independence could skew differences between sub-colonies (i.e., once individual differences were accounted for, there might be no difference between locations).

L167 Here the authors state that a QIAamp DNA Stool Mini Kit was used. Are there any pros and cons of using this product? I ask because in a recent study I read, the authors instead used a DNeasy PowerSoil Kit for extracting DNA from scat samples - see Harper, L. R., et al. (2020). Using DNA metabarcoding to investigate diet and niche partitioning in the native European otter (Lutra lutra) and invasive American mink (Neovison vison). Metabarcoding and Metagenomics 4: e56087.

L165-174 What was used to homogenise the samples - a tissue lyser?

L166 Did the authors consider using technical replicates from the samples before pooling?

L177 It would be useful to state the full name of the primers used.

L185 Did the authors consider using positive and negative controls with the PCR runs?

L248 What was the number of sequences that the samples were rarefied to? It could be useful to provide the rarefaction curves in the Supporting Information.

L286 Did the removal of singletons have any effect on the results?

L288 Probably better to say "did not match"

L293 So this is another way of saying that 12 samples only had unassigned OTUs, and thus were not used in the analyses? 


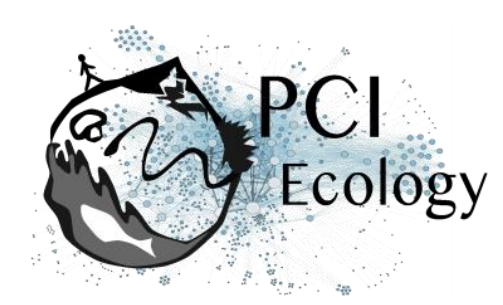

L295 I felt that the results could have done with some multivariate analyses to assess changes in overall prey communities - for instance Non-Metric Multidimensional Scaling plots with a PERMANOVA model to test differences between sampling dates and sub-colony location.

L483 Might be better to use concordance here instead of "coherence"

Reviewed by Babett Günther, 26 Nov 2020

Download the review 